\title{
El hispanismo británico: Estado actual y perspectivas
}

\section{Philip Deacon}

Arbor CLXVIII, 664 (Abril 2001), 595-607 pp.

En esta reflexión sobre el hispanismo británico, en lugar de especular sobre cuáles de las tendencias actuales llegarán a dominar en el futuro, voy a describir las fuerzas operantes en este campo que constituyen la situación en este momento y que por tanto contienen en germen las corrientes futuras. El cuadro resultante comprende corrientes cuyas posibilidades para desarrollos futuros no se han agotado, además de líneas innovadoras que están ensanchando y enriqueciendo las posibilidades investigadoras de hoy. Para completar el panorama hago un repaso de los medios editoriales e instituciones que facilitan y apoyan el hispanismo en el Reino Unido.

El talante positivo que predomina en el hispanismo británico actual se remonta a unos importantes cambios de tipo político ocurridos en el Reino Unido y España. La incorporación del Reino Unido a la Comunidad Económica Europea en 1973 supuso un renovado compromiso político y cultural con los países vecinos, y el posterior ingreso de España en 1986 implicó una continua convergencia de miras de los dos países. La pertenencia a la Unión Europea, junto con la aproximación sociocultural que ofrece la industria turística española para muchos británicos, les ha abierto los ojos al concepto de España en sus manifestaciones más variadas. Ese mayor conocimiento ha ido acompañado de una interrogación a nivel más científico sobre el concepto de cultura, ahora comúnmente entendido como «todo lo que hace el hombre como ser social». Anteriormente la cultura española significaba para un universitario británico la lengua, literatura e historia política de España, mientras que hoy en día es probable que exista una visión más completa y diversa del país y que su cultura se entienda en el sentido plural de esa palabra, que abarca todas las maneras en que los españoles 
expresan su identidad, sea a través del cine, el deporte, el baile, la música, las fiestas e incluso los edificios y la cocina. La cultura española se comunica cada vez más a través de imágenes televisivas y el británico de la calle fácilmente reconoce personajes y objetos destacados de la cultura española como José Carreras, Pedro Almodóvar, el Museo Guggenheim de Bilbao, o una sala de fiestas de Ibiza.

\section{Los «estudios culturales» y otros campos destacados}

En la actualidad existe una gran diversidad en el hispanismo británico; la ampliación de temas ha sido fomentada por las necesidades de enseñar y transmitir a las nuevas generaciones las innovaciones más importantes en cada terreno. El hispanismo ha seguido de cerca los debates en el campo de la teoría literaria (o cultural) que han centrado la atención en los departamentos hermanos dedicados a la cultura nacional (Jordan, 1990). Las aproximaciones metodológicas derivadas del deconstruccionismo, el análisis psicoanalítico (Sinclair, 1993), el feminismo, los estudios "gay", el postmodernismo, y otros, han influido en los métodos empleados por hispanistas británicos para entender la cultura española (Smith, 1992). En este momento no existe ninguna ortodoxia dominante como podría haberse argüido hace cuatro décadas cuando el hispanismo británico estaba menos desarrollado (Marichal, 1990). Todo parece aceptarse en los foros donde el hispanista inglés, galés, escocés o norirlandés presenta sus investigaciones. Y, como se demostrará abajo, el número de revistas en que aparecen publicadas las investigaciones se ha ampliado para dar cabida a esta pluralidad.

Si hubiera que señalar una tendencia importante que se ha perfilado en los estudios filológicos del hispanismo británico en la última década, tendría que ser los llamados «estudios culturales», término globalizador que sirve para subrayar los contextos que comparten todos los fenómenos culturales (Inglis, 1993; Eagleton, 2000).

El texto que mejor sirve como muestra de una aproximación a España desde esta perspectiva es el libro Spanish Cultural Studies: An Introduction, coordinado por Helen Graham y Jo Labanyi, la primera historiadora, la otra originariamente crítica literaria (Graham, 1995). El libro proclama su enfoque en la introducción: su concepto de la cultura abarca la identidad, la sexualidad, los nacionalismos, los medios de comunicación, el cine, la arquitectura, la sociolingüística, fenómenos como «la movida», etc., adoptando una óptica que cuestiona los principios de una cultura de élite desde una perspectiva de oposición a la cultura 
establecida, subrayando incluso el aspecto postmoderno de la cultura española actual. El libro, publicado por la Oxford University Press, no es un fenómeno único. La Cambridge University Press respondió con un libro coordinado por un norteamericano, David Gies, en que muchos de los temas -identidad nacional y regional, medios, arte, etc.- y de los autores se repetían. El Cambridge Companion to Modern Spanish Culture es más ecléctico, con muchos autores norteamericanos además de británicos y españoles, y no se nota un deseo de adoptar una única línea política o de oposición sino que se reflejen distintas perspectivas tanto de método como de compromiso político (Gies, 1999). Y como las editoriales parecen ver un campo nuevo para sus productos, la editora Arnold ha lanzado Contemporary Spanish Cultural Studies, coordinado por Barry Jordan y Rikki Morgan-Tamosunas (Jordan, 2000). Cada nueva aportación responde al libro anterior, variando perspectivas y avanzando el debate. De inspiración parecida, aunque en forma de libro de consulta, es la Routledge Encyclopedia de Contemporary Spain, dirigida por Eamonn Rodgers y un equipo de coordinadores (Rodgers, 1999). En este caso consta el deseo de ofrecer una obra de referencia al estudiante de lengua inglesa interesado por la cultura española. Y como consagración de la estrella ascendente de los estudios culturales, está a punto de aparecer una nueva revista, el Journal of Spanish Cultural Studies, dirigida por la misma Jo Labanyi y un equipo de codirectores (Paul Julian Smith, Alberto Moreiras, Teresa Vilarós y Josep-Antón Fernández). Su línea editorial es «cuestionar las nociones establecidas de la cultura española y del hispanismo a través de trabajos de innovación teórica y crítica». Lo que trasciende de este fervor editorial es la apuesta por la popularidad de esta aproximación multidisciplinar a la cultura española y el deseo de sus protagonistas de innovar.

El hetho de que el estudio del cine se acoja bajo el signo de los estudios culturales no significa que no debe figurar como un importante campo autónomo. El libro de John Hopewell, Out of the Past: Spanish Cinema after Franco (1986), fue un jalón que permitió que los cursos de cine español tuvieran un texto de referencia en que basar los estudios. Sin embargo, una ojeada a las recientes bibliografías sobre el cine español demuestra la fuerte presencia de historiadores y críticos británicos aunque algunos quizás no se sientan adscritos al hispanismo. La atención investigadora se ha prestado preferentemente a nombres como Luis Buñuel (Evans, 1995), Carlos Saura (Edwards, 1995), Víctor Erice (Riley, 1984) y cada vez más Pedro Almodóvar (Smith, 1994). Los estudios monográficos sobre directores e incluso análisis de películas individuales han encontrado cabida en series importantes como las 
guías del British Film Institute (Evans, 1996) y la nueva serie sobre cine de la Cambridge University Press, Cambridge film handbooks. Varios hispanistas inicialmente especializados en literatura han visto el análisis de películas como lógica extensión de sus trabajos de crítica literaria (Fiddian, 1988); sus estudios se han difundido mucho y varios de los títulos han sido traducidos al español.

El interés por el cine como forma artística ha sido fomentado por instituciones oficiales como el British Film Institute y sus filiales en varias grandes ciudades del Reino Unido. El conocimiento del cine específicamente español, sin embargo, ha sido secundado por las distintas sedes del Instituto Cervantes (Londres, Leeds y Manchester) que han montado festivales de cine español con hispanistas británicos y a la vez invitando a destacados personajes españoles con el fin de dar a conocer mejor las últimas novedades. En paralelo los congresos y coloquios del hispanismo británico han acogido el estudio del cine como componente fundamental de sus actividades. En suma, se puede concluir que el estudio del cine español se halla ya firmemente establecido en los programas universitarios, y por tanto será materia básica del hispanismo futuro.

Otro aspecto destacado del hispanismo británico reciente es el auge de los estudios sobre traducción. Existe un centro de traducción literaria en la Universidad de East Anglia, dirigido por Peter Bush, y varios profesores de otras universidades traducen textos españoles para un público de habla inglesa. Se celebran congresos en el British Centre for Literary Translation que reúnen a especialistas de todas las lenguas, incluido el castellano, y ciertas editoriales han promocionado las obras de autores españoles pasados y presentes en series de prestigio (Oxford World's Classics, Penguin Classics, etc.). Mención especial merecen las traducciones de textos teatrales por especialistas como John Edmunds (1999), Gwynne Edwards (1987-1994), David Johnston (1992), y Nicolas Round. La editorial Aris and Phillips ha dedicado atención especial a las traducciones de obras españolas, publicando una impresionante serie de ediciones bilingües a cargo de destacados especialistas.

El tercer campo que interesa mencionar por haber ocupado la atención de un destacado número de hispanistas británicos es la literatura de mujeres y el terreno relacionado de la crítica cultural enfocada a través del género. No es extraño que hayan sido las hispanistas las que han prestado más atención a escritoras españolas (Davies, 1993), pero también el papel de la mujer en la sociedad española (Jones, 1997) y una aproximación feminista a la cultura española han sido temas de interés predilecto de estas investigadoras. De pasada, debe 
El hispanismo británico: Estado actual y perspectivas

mencionarse que las últimas dos décadas han presenciado un mayor protagonismo de mujeres en el hispanismo británico en general. Es significativo, por ejemplo, que en la dirección de las principales revistas del hispanismo británico haya un número igual de hombres y mujeres.

El cuarto campo que quiero destacar es el estudio de las culturas catalana, gallega y vasca. Las nacionalidades que constituyen España siempre han interesado a los hispanistas británicos, pero la creación de las Comunidades Autónomas ha llamado la atención de manera especial sobre el concepto de la identidad. Desde 1954 la cultura catalana tiene su propia organización de estudio y apoyo en la Anglo-Catalan Society, que publica monografías y monta congresos para fomentar las investigaciones en este campo. La más reciente creación de lectorados de catalán financiados por la Generalitat de Cataluña en algunas universidades extiende los conocimientos de la lengua catalana entre los estudiantes británicos y anima a los profesores a investigar en ese campo. En la Universidad de Birmingham existe un Centro de Estudios Gallegos que fomenta el interés por la cultura de Galicia. La cultura vasca asimismo es tema de investigación de varios estudiosos, especialmente historiadores (Sullivan, 1988). Varios profesores de lingüística dedican atención tanto práctica como teórica a las diversas lenguas cooficiales del estado español. De fecha reciente son la gramática comprensiva de la lengua catalana (Wheeler, 1999) y la historia de la lengua vasca (Trask, 1997) que figuran en importantes series publicadas por la editorial Routledge.

\section{Los órganos potenciadores de la investigación: Las editoriales}

Las corrientes a las que acabo de referirme son una muestra de cómo la actividad editorial acompaña la renovación y ampliación del hispanismo británico. La percepción de que los estudios hispánicos se han establecido como campo en vías de expansión en el Reino Unido $\mathrm{y}$ otros países de habla inglesa, y que existe un público listo para acoger las nuevas aportaciones universitarias es evidente en la publicación de un número de textos fundamentales. Hace una década la editorial Arnold publicó una gramática descriptiva del español para angloparlantes (Butt, 1988). La aparición de este manual de unas quinientas páginas por fin proporcionó una herramienta de primera importancia para la enseñanza de la lengua española en el Reino Unido. De manera semejante, el diccionario, ya antiguo, de la editorial 
Collins, dirigido en su primera edición por el destacado hispanista británico Colin Smith (1971), ha vuelto a editarse en ediciones ampliadas y puestas al día, proporcionando otra herramienta imprescindible. En 1994 la Oxford University Press lanzó un gran diccionario bilingüe competidor, demostrando la creciente demanda en el sector.

Varias editoriales relacionadas con los estudios hispánicos han tenido una proyección fuera del Reino Unido por publicar igualmente en lengua española. La editorial Támesis, ahora incorporada en Boydell and Brewer, sigue publicando ediciones y estudios de literatura, historia, arte, música y de otros temas culturales españoles. Después de la muerte en 1999 de su fundador, John Varey, su labor editorial continúa, aunque su sede se había trasladado hacía tiempo a España y su consejo de redacción refleja ahora una fuerte influencia española además de británica. La Liverpool University Press, editora de la distinguida revista Bulletin of Hispanic Studies, ha lanzado una serie paralela de monografías (Textual Research and Criticism Series) formada por estudios y ediciones, algunos en inglés pero otros editados en castellano.

Una editorial independiente mencionada arriba, Aris and Phillips, cuenta con una importante lista de estudios y ediciones de textos españoles para uso universitario. Su serie más destacada es la dedicada a ediciones bilingües de textos clásicos españoles. Los encargados de los distintos volúmenes, que incluyen un alto porcentaje de británicos, han preparado textos cuidados de obras españolas acompañadas de traducciones que las hagan accesibles a lectores de habla inglesa. Una nueva iniciativa editorial comercial es la serie de textos españoles dirigida por Paul Lewis-Smith, y editada por Bristol Classical Press, filial de la casa editora londinense Gerald Duckworth. Desde 1995 la Bristol Classical Press ha publicado ediciones críticas de textos importantes, y hace poco la editorial se extendió a la publicación de monografías sobre temas españoles.

Otra editorial universitaria, la de Manchester, se ha renovado en la pasada década, publicando más libros de interés hispánico, no sólo ediciones escolares y universitarias de textos importantes en una serie dirigida por Peter Beardsell, sino también estudios de política (Gibbons, 1999) y cine (Jordan, 1998). Una institución universitaria más pequeña que publica investigaciones sobre la cultura española es el Trinity and All Saints College de Leeds. Centrándose en los trabajos presentados en congresos y coloquios celebrados en Leeds, el Colegio ha editado una serie de libros en que se reúnen trabajos importantes sobre temas hispánicos tan diversos como la novela negra (Rix, 1992), el cine, o las relaciones con la Comunidad Europea (Cooper, 1995). Otra editorial 
especializada que ha llevado a cabo una importante tarea al dar a luz los trabajos de hispanistas británicos es la Edwin Mellen Press. A través de su oficina británica en Lampeter esta editora norteamericana publica monografías sobre temas hispánicos (Davies, 1993), tanto en inglés como en español, a veces con tiradas cortas, pero que hacen llegar a manos de un público interesado estudios, ediciones y obras especializadas que de otra manera no aparecerían.

Las antiguas editoriales universitarias de Oxford y Cambridge han seguido su tradición de editar libros importantes dedicados a la cultura española. Los títulos recientemente publicados tratan todos los campos del hispanismo: literatura, historia, arte, cine, política, economía. Una novedad digna de destacar es el deseo de la Cambridge University Press de dar mayor salida a sus autores en el mundo hispánico; si en un primer momento los derechos fueron cedidos a una editorial española, ahora es la misma editorial la que a través de su filial española imprime y comercializa sus productos en España e Hispanoamérica en ediciones españolas (Gies, 1996). No obstante, las editoriales españolas siguen de cerca las novedades sobre España publicadas en el Reino Unido y con loable prontitud los estudios importantes suelen aparecer poco después en castellano, y a veces, casi en paralelo con la edición inglesa. Y ciertos estudios, como los del historiador Paul Preston, a veces se publican antes en España que en el Reino Unido (Preston, 1986).

\section{La revistas científicas}

Una novedad en el mercado de revistas, emprendida con el deseo de ampliar el terreno de los estudios hispánicos, es Tesserae, dirigida desde Cardiff University por los profesores Jordi Larios y Montserrat Lunati. La publicación aparece dos veces al año, tiene un aspecto novedoso e intenta abarcar la plenitud de los estudios españoles e hispanoamericanos en el Reino Unido, publicándose artículos y reseñas en inglés, español y catalán. Su distribución y comercialización está en manos de una editorial de prestigio y es de esperar que la calidad de sus aportaciones le ayude a afianzarse en el mercado. Otra iniciativa parecida fue la revista de la Queen Mary and Westfield College, la Journal of Hispanic Research, publicada entre 1992 y 1995. Según su declaración de principios, la revista se dedicaba «a las lenguas, literaturas, cine, artes dramáticas e historia intelectual de España e Hispanoamérica», y en los primeros números el intento de provocar 
el debate sobre las líneas futuras del hispanismo encontró cabida en el «Open Forum» del periódico (Round, 1992; Hart, 1993). El mismo equipo directivo lanzará una nueva revista en 2000: Hispanic Research Journal.

He hecho mención ya del veterano Bulletin of Hispanic Studies, iniciado en Liverpool en 1923. Como resultado de un desacuerdo sobre la dirección de la revista, el comité editorial decidió trasladar su sede institucional en 1995 a la Universidad escocesa de Glasgow. Posteriormente la Liverpool University Press reivindicó la titularidad de la revista ante un juez en Escocia, juicio que perdió (Bulletin, 1996). La falta de claridad sobre la situación terminó con la publicación desde 1996 de dos revistas con el mismo nombre y aspecto, y hasta la fecha no se ha encontrado otra solución.

Esta expansión en el terreno de las revistas científicas tiene que sumarse a la existencia de otras ya firmemente establecidas. Romance Studies, publicado en Swansea, se dedica también a las demás lenguas románicas, al igual que el Forum for Modern Language Studies, editado por la Oxford University Press para St Andrews University y la Modern Language Review, editada por la Modern Humanities Research Association. No podemos cerrar este capítulo sobre las publicaciones periódicas sin mencionar la aparición de Donaire, revista semestral de la Consejería de Educación y Ciencia de la Embajada de España en Londres, que acoge trabajos de hispanistas británicos de variada naturaleza. Su lanzamiento es una muestra más de cómo el hispanismo británico actual corre parejo con el hispanismo de España.

\section{Los órganos institucionales del hispanismo británico}

El hispanismo británico tiene dos asociaciones que representan a sus miembros y encauzan sus actividades. La Association of Hispanists of Great Britain and Ireland (AHGBI) fue creada en 1955 para coordinar las actividades conjuntas de los hispanistas en universidades. Celebra un congreso anual como foro para comunicaciones sobre temas propuestos por los organizadores o en secciones dedicadas a distintas ramas de estudios (literatura medieval, teoría de la literatura, lingüística, etc.). Otra agrupación, de creación más reciente (1987), es la Association for Contemporary Iberian Studies (ACIS), que en sus inicios comprendía a hispanistas de los colegios politécnicos (convertidos en universidades en 1992) que querían promocionar un enfoque distinto de la investigación, uno más acorde con la enseñanza de aspectos de España que 
no ocupaban el primer plano en las universidades, es decir la política, economía y sociología de España, además de la lingüística aplicada. La ACIS marcó distancias con la AHGBI por restar importancia al estudio de la literatura, tema que solía dominar en los congresos de la AHGBI. En su establecimiento formal en 1988 la ACIS inauguró una revista semestral denominada ACIS, que en 1996 se convirtió en el International Journal of Iberian Studies.

La labor del hispanismo británico recibe el apoyo de las instituciones representativas del Gobierno de España, y desde que se establecieron las tres sedes del Instituto Cervantes en el Reino Unido, la cooperación y respaldo recibidos por las dos asociaciones oficiales del hispanismo británico han sido extensos. Muchas de las actividades programadas por el Instituto Cervantes se hacen en colaboración con hispanistas del Reino Unido; numerosos coloquios y actos culturales organizados en conjunto han tenido mayor trascendencia debido al apoyo dado por el Instituto, sea proporcionando una sede para su celebración, sea por encargarse de la asistencia de destacadas personalidades españolas. El Gobierno español a través de varios ministerios apoya e incentiva la investigación de profesores británicos en España. El Ministerio de Asuntos Exteriores convoca Becas para Hispanistas que. permiten la estancia durante periodos de uno o dos meses para llevar a cabo investigaciones en archivos, bibliotecas y otras instituciones en España.

Una iniciativa positiva del Gobierno británico con respecto al fomento de la investigación en el terreno del hispanismo se produjo en octubre de 1998 con la creación del Arts and Humanities Research Board (AHRB). Las otras grandes divisiones de la investigación científica universitaria (Ciencias Sociales, Medicina, etc.) tenían un consejo nacional para orientar, administrar y financiar sus actividades, quizás porque recibían fondos sustancialmente superiores. En el año referido, a raíz del informe encargado por el Gobierno a un comité presidido por Sir Ronald Dearing (1997), la labor de la British Academy relacionada con la asignación de recursos a la investigación pasó al AHRB, un organismo parecido a los demás consejos de investigación, para así promocionar áreas que hasta entonces recibían sensiblemente menos recursos que sus semejantes (un investigador de filología recibía, por ejemplo, como promedio un $7 \%$ de lo que recibía uno de ciencias sociales). Un resultado de la creación del AHRB ha sido la financiación de proyectos de investigación más ambiciosos, un sistema de sabáticos de investigación, recursos para financiar investigaciones postdoctorales, becas para asistir a congresos internacionales, etc. Este aumento de financiación gubernamental dedicada a las humanidades —donde se 
comprende la mayor parte del hispanismo- está en sus inicios pero los actuales planes prometen resultados notables en el futuro.

El AHRB en 1998 absorbió varias de las funciones de la antigua British Academy. Conviene, sin embargo, mencionar algún que otro proyecto iniciado bajo los auspicios de ésta. El Pérez Galdós Editions Project localizado en la Universidad de Sheffield fue establecido en 1996 bajo la dirección de Nicolas Round, con un comité internacional que incluye a galdosistas españoles. El proyecto tiene como eje un Centro universitario dedicado a la preparación de textos críticos del autor canario - en la actualidad Rhian Davies prepara ediciones de las novelas de Torquemada- que se divulgarán utilizando métodos tanto tradicionales como electrónicos. En torno a la tarea editorial se montan coloquios y talleres de trabajo que reúnen a galdosistas de todo el mundo. Otro ejemplo de un proyecto auspiciado por la British Academy ha sido la catalogación de la Colección Eliot-Phelips de libros y documentos españoles que se encuentran en la Biblioteca de la Universidad de Londres. Esta colección importante de impresos, planos y otros objetos ha sido cuidadosamente catalogada, y se celebró un coloquio en 1999 para dar a conocer mejor su existencia.

Una significativa participación española en la investigación hispanística en el Reino Unido procede desde hace varias décadas de la Fundación Cañada Blanch, con sede española en Valencia. Esta Fundación cultural lleva fomentando el hispanismo británico desde hace mucho tiempo a través de un sistema de becas de ayuda a la investigación, y en 1996 amplió sus actividades estableciendo dos Centros en el Reino Unido: uno en la London School of Economics bajo la dirección del historiador Paul Preston y otro en Manchester bajo la dirección del medievalista Jeremy Lawrence. Los dos centros promocionan investigaciones a través de becas pero también varias actividades afines; financian publicaciones, montan coloquios, organizan visitas y se ocupan de todo lo que pueda promocionar el interés por España y su cultura. Una institución semejante británica, de larga dedicación al estudio y promoción de la cultura española y latinoamericana en el Reino Unido, es Canning House en Londres. Este centro monta coloquios y cursos especializados orientados a divulgar el conocimiento de la lengua española y de los países que la hablan, y por tanto facilita los contactos entre hispanistas y los interesados por los campos que investigan. De importancia especial son los cursos para profesores de colegio, que así se ponen al día de las últimas novedades.

No puede terminarse este repaso de las instituciones que apoyan la investigación sobre España en el Reino Unido sin mencionar otras 
dos entidades. La British Library tiene una colección extraordinaria de libros y manuscritos españoles que proporcionan un apoyo fundamental a la investigación. Este centro tiene un equipo de bibliotecarios especializados en la cultura española que cuidan y amplían las colecciones además de publicar sus propios trabajos de investigación (Whitehead, 1994). Estos especialistas participan en los organismos del hispanismo británico ya mencionados, manteniendo contactos con los investigadores en universidades y cooperando dentro de lo posible en promocionar el hispanismo. La segunda institución nacional, la Royal Academy of Arts, monta exposiciones de arte con gran regularidad e incluye artistas españoles entre los que se exhiben. Esta Academia mantiene estrechos contactos con España y cuando en 1994 preparó una exposición sobre Goya lo hizo en colaboración con el Museo del Prado, y organizó conferencias para acompañar la muestra, contando con la participación de expertos en la obra del pintor aragonés como Juliet Wilson-Bareau, una de las coordinadoras de la exposición (Wilson-Bareau, 1994).

\section{Conclusión}

El breve recorrido antecedente, necesariamente parcial y subjetivo, apunta a tendencias que indican un futuro lleno de vitalidad para el hispanismo británico. La existencia de una sólida infraestructura institucional además de las múltiples redes de relaciones y contactos personales son una prueba de los fundamentos sobre los que se realizan las actividades del hispanismo en el Reino Unido. La diferencia notable con respecto a la situación de hace veinticinco años es la firmeza y confianza del apoyo recibido de España a través de muchas vías. Es evidente también que los mismos hispanistas británicos se encuentran más íntimamente conectados con España. Los medios de comunicación modernos como el correo electrónico ponen a los investigadores en contacto de la manera más inmediata, lo que permite estrechar aún más la colaboración entre individuos e instituciones de los dos países.

\section{Bibliografía}

Bulletin. 1996. Bulletin of Hispanic Studies (University of Glasgow), LXXIII, vII-XV. Butt, John, y Carmen Benjamin. 1988. A New Reference Grammar of Modern Spanish, Londres, Edward Arnold.

Cooper, T.M. (ed.). 1995. Spain in Europe, Leeds, Trinity and All Saints College. 
Davies, Catherine (ed.). 1993. Women Writers in Twentieth-Century Spain and Spanish America, Lampeter, Edwin Mellen Press.

[Dearing, Ronald]. 1997. Higher Education in the Learning Society: The National Committee of Inquiry into Higher Education, Londres, The National Committee of Inquiry into Higher Education.

Eagleton, Terry. 2000. The Idea of Culture, Oxford, Blackwell.

Edmunds, John (tr.). 1999. Federico García Lorca, Four Major Plays, Londres, Penguin.

Edwards, Gwynne (tr.). 1987-1994. Federico García Lorca, Plays, Londres, Methuen. 3 vols.

- 1995. Indecent Exposures. Buñuel, Saura, Erice and Almodóvar, Londres. MARIoN BOYARS.

Evans, Peter W. 1995. The Films of Luis Buñuel, Oxford, Oxford University Press.

- 1996. Women on the Verge of a Nervous Breakdown, Londres, British Film Institute.

Fiddian, Robin, y Peter evans. 1988. Challenges to Authority: Fiction and Film in Contemporary Spain, Londres, Támesis.

Gibbons, John. 1999. Spanish Politics Today, Manchester, Manchester University Press.

Gies, DAvid T. 1996. El teatro en la España del siglo XIX, tr. Juan M. Seco, Cambridge, Cambridge University Press.

- (ed.). 1999. The Cambridge Companion to Modern Spanish Culture, Cambridge, Cambridge University Press.

Graham, Helen, y Jo Labany (ed.). 1995. Spanish Cultural Studies: an Introduction. The Struggle for Modernity, Oxford, Oxford University Press.

HaRt, StePhen. 1992. "Mientras que en mi casa estoy, rey soy"»: More on the Politics of Hispanism", Journal of Hispanic Research, 1, 415-423.

Hopewell, John. 1986. Out of the Past. Spanish Cinema after Franco, Londres, British Film Institute.

InGLIS, FRed. 1993. Cultural Studies, Oxford, Blackwell.

Johnston, DAvid (tr.). 1992. Great Pretenders and The Gentleman from Olmedo, Bath, Absolute Press.

Jones, ANny B. 1997. Women in Contemporary Spain, Manchester, Manchester University Press.

JordAn, Barry. 1990. British Hispanism and the Challenge of Literary Theory, Warminster, Aris and Phillips.

- y Rikk Morgan-Tamosunas. 1998. Contemporary Spanish Cinema, Manchester, Manchester University Press.

- , y Rikki Morgan-Tamosunas (ed.). 2000. Contemporary Spanish Cultural Studies, Londres, Arnold.

MARICHAL, GEORGE. 1990. "An introduction to the ideology of Hispanism in the US and Britain", en Peter W. Evans (ed.), Conflicts of Discourse: Spanish Literature in the Golden Age, Manchester, Manchester University Press, 1-25.

The Oxford Spanish Dictionary. Spanish-English/English-Spanish. 1994. Oxford, Oxford University Press.

Preston, Paul. 1986. Las derechas españolas en el siglo XX: autoritarismo, fascismo y golpismo, Madrid, Sistema.

RILEY, EDWARD. 1984. "The story of Ana in El espíritu de la colmena», Bulletin of Hispanic Studies, LXI, 491-497.

RIx, Rов (ed.). 1992. Leeds Papers on Thrillers in the Transition. "Novela negra" and Political Change in Spain, Leeds, Trinity and All Saints College. 


\section{El hispanismo británico: Estado actual y perspectivas}

Rodgers, EAmonn (ed.). 1999. Encyclopedia of Contemporary Spanish Culture. Londres, Routledge.

Round, Nicholas G. 1992. "The Politics of Hispanism Reconstrued», Journal of Hispanic Research, 1, 134-147.

Sinclair, Alison. 1993. The Deceived Husband: A Kleinian Approach to the Literature of Infidelity, Oxford, Oxford University Press.

Smith, Colin (ed.). 1971. Collins Spanish-English, English-Spanish Dictionary, Glasgow, Collins.

Smith, PaUl J. 1989. The Body Hispanic. Gender and Sexuality in Spanish and Spanish American Literature, Oxford, Oxford University Press.

- 1992. Representing the Other. "Race», Text and Gender in Spain and Spanish American Narrative, Oxford, Oxford University Press.

- 1994. Desire Unlimited. The Cinema of Pedro Almodóvar, Londres, Verso.

Sullivan, John. 1988. ETA and Basque Nationalism. The Fight for Euskadi, 1890-1986, Londres, Routledge.

Trask, R. L. 1997. The History of Basque, Londres, Routledge.

Wheeler, Max W., Alan Yates y Nicolau Dols. 1999. Catalan: A Comprehensive Grammar, Londres, Routledge.

[WhiteHEAd, Harold] (ed.). 1994. Short-title Catalogue of Eighteenth-Century Spanish Books in the British Library, Londres, The British Library. 3 vols.

Wilson-Bareau, Juliet. 1994. Goya: Truth and Fantasy. The Small Paintings. Exhibition Curated by Juliet Wilson-Bareau, Manuela B. Mena Marqués, Londres, Yale University Press. 